\title{
Internet Access at Home and its Relationship to Well-being in Deprived Areas of London
}

\author{
Ilona Boniwell ${ }^{1}$, Evgeny N. Osin ${ }^{2, *}$ and Adrian Renton ${ }^{3}$
}

\author{
${ }^{1}$ Positran (Goupillères, France) and Anglia Ruskin University, Cambridge, UK; ${ }^{2}$ National Research University Higher \\ School of Economics, Moscow, Russia; ${ }^{3}$ Institute for Health and Human Development, University of East London, \\ London, UK
}

\begin{abstract}
Purpose: The existing studies of the association between Internet usage and well-being have produced contradictory results. This study explores the associations between Internet access at home and well-being, as well as other lifestyle variables. Design/methodology/approach: The study was done in a probability sample of 800 community-dwelling adults aged 16 and over in six most deprived areas of the Redbridge borough of London. Using face-to-face interviews, information on the demographics, lifestyle, Internet access at home, happiness, trait hope, and subjective health was obtained. Path analysis and structural equation modelling were used to investigate the associations between Internet access and well-being, controlling for demographic variables. Findings: Respondents with home Internet access had stronger social ties with friends and relatives, engaged in a wider repertoire of community creative activities and cultural events, and reported having higher social support. Controlling for demographic variables, Internet access at home was a weak but statistically significant predictor of happiness, agency, and absence of mental health problems. The effect of home Internet access on happiness was partially mediated by social ties. Research limitations/implications: The correlational nature of the study forbids making causal inferences. The data suggest that people with low socioeconomic status may derive wellbeing benefits from having access to information technology which can serve as an instrument for social integration. Originality/value: The data provide a demographic snapshot of the digital divide in one of the most deprived areas of London.
\end{abstract}

Keywords: Digital divide, happiness, internet access, low socioeconomic status, subjective health, subjective well-being.

\section{INTRODUCTION}

For many people in Britain the Internet has become an integral part of daily life. With our widespread reliance on the Internet for communication, information gathering and consumer behaviour, it is essential to understand its effects on health and well-being of the population.

Relationships between Internet access/usage and Internetrelated psychological health have been a major research focus in the field of cyber-psychology. However, despite nearly one and a half decades of research, there remain substantial disagreements with regard to the nature and value of Internet's impact on our psychological lives.

A longitudinal study by Kraut et al. [1] was one of the first to assess the impact of Internet use on social involvement and psychological well-being on the opportunity sample of community dwellers freshly exposed to computers and Internet. Contrary to initial predictions, heavier users became less socially involved and more depressed 12-18 months later. However, a three-year follow up study of the original participants found that the original negative effects dissipated, with both depression and loneliness declining over time [2]. Interestingly, the more hours the average respondent spent on the Internet, the more (not less) time they also

*Address correspondence to this author at the Psychology Department HSE, Myasnitskaya ul. 20, Moscow 101000, Russia;

Tel: (+7) (916) 631-5719; Fax: (+7) (499) 178-0392;

E-mails: eosin@hse.ru and evgeny.n.osin@gmail.com spent face-to-face with family and friends. An additional study demonstrated both an increase in positive affectivity and stress for new Internet users. Explanations offered by the authors of the original study for this discrepancy in the findings include maturation of participants and changes in the ways they used the Internet [2].

Various other studies on the relationships between measures of Internet use and positive and negative indicators of well-being (including depression, loneliness, life satisfaction, positive and negative affect) produced mixed results, ranging from positive to non-significant and negative relationships (see [3], for a detailed summary of findings). A metaanalysis of 40 studies [4] indicated a very small detrimental effect $(\mathrm{r}=-.05)$ of Internet use on well-being. Sum et al. [5] suggest that the relationship between Internet use and wellbeing is complex, with the Internet having different effects depending on its use.

Examination of the motives behind Internet use suggests that different motives result in different behaviours thus leading to different psychological effects. About half of the total variance in the Internet use is accounted for by two major motives - socio-affective regulation and good-andinformation acquisition. Internet use driven by socioaffective regulation motives negatively influences psychological well-being through reducing off-line social integration, whilst the reverse is true for good-and-information acquisition [6]. Using a sample of 500 children, Jackson et al. [7] similarly demonstrated the detrimental effects of Internet 
use for communication purposes (all other uses were associated with greater psychological well-being). The study done by Sum et al. [5] brought further intricacy into our understanding of the impact of socio-affective Internet behaviours by finding that a greater use of the Internet as a communication tool with relatives and friends was associated with a lower level of social loneliness. In contrast, a greater use of the Internet to find new people was associated with higher levels of emotional loneliness. A number of recent studies indicate positive associations between social networking and subjective well-being indicators $[8,9]$, however, the effect sizes are modest, suggesting that Internet use outcomes may be contingent on individual goals and other personality factors.

Convincing accounts have been put forward for both the negative and the positive effects of Internet use. The negative ones range from addiction development [10]; disruption in meaningful off-line social ties [11], "displacement" of face-to-face interactions and activities by the Internet [12] and reduced amount of time spent in activities outside the home. However, some of the Nie and Hillygus' conclusions have been challenged after a closer examination of their findings, in which $95 \%$ of the total sample reported no decreases in time spent with family and friends [13]. On the positive side, Internet use appears to signal higher level of thinking and ability [14], impacts schools satisfaction [15], can positively affect disruptive events and moods [16], and benefit social support and relationship development [17]. It is also associated with greater self-esteem [18] and self-efficacy [19]. One of the reasons for the beneficial effects of the access/use of Internet is the frequent experience of flow states whilst on-line. Chen, et al. [20] provided evidence to suggest that usage of Internet facilitates flow, generating an enjoyable, absorbing experience with total involvement and concentration. Furthermore, the evidence consistently exposes the positive effect of Internet use on off-line community involvement. A random national survey by Katz et al. [21] showed that the more time Internet users spent on-line, the more likely they were to belong to off-line religious, leisure, and community organisations, and be more aware of their communities compared to non-users. Similar results were reported by Gross et al. [22] and Wellman et al. [23] from teenage and Internet convenience samples.

The majority of past research on Internet and well-being has focused on children [7], adolescents [24-26], college students [15], older people [5, 27, 28], and comparisons between younger and older populations [29]. To date, few studies have looked at 'ordinary' community dwellers or relied on probability sampling techniques in their selection of participants. Valkenburg and Peter [3] point out that the vast majority of reported studies used depression and loneliness measures as indicators of well-being, with only a few notable exceptions published to date $[2,3,6,18,22]$. They also suggest that inconsistencies in findings with regard to Internet use and well-being may be explained by treating Internet use as a unitary construct. Indeed, it is possible to distinguish between different aspects related to Internet use, including Web access, email communication, social networking/chatting (further breaking down into communication with family/friends vs. unknown people), blogging, gaming and other forms of entertainment, downloading programmes and files, shopping and web surfing for information purposes.

Throughout the past 15 years, the research focus in the field has been gradually shifting from the differences in internet access (between the "haves" and "have nots"), labelled as the first-level digital divide, towards the differences in information and communication technology skills ('internet literacy', 'second-level digital divide' [30]) and those in the motives and types of online activities. Within the latter research paradigm, the term 'Internet use' is mainly used to refer to the quality, as well as quantity, of time spent online by active Internet users, rather than to the fact of being such a user. This shift was based on the idea that with increasing Internet penetration nearly everyone would have Internet access at some point, and inequality related to Internet use would become more important [31].

However, at present, this is still not the case. Firstly, Internet adoption has not yet become universal even in the developed countries. For instance, even in the UK, one of Europe's most well-connected economies, as of 2014, there are over 6 million people who have never used the Internet (13\% of adults aged 16 and over; down from $17 \%$ in 2011) [32]. National surveys reveal that internet users and nonusers in the UK tend to differ strongly in terms of age, disability, and income, whereas differences in ethnicity are relatively minor [32]. These data suggest that research of the psychological and social benefits of Internet access, particularly in socially disadvantaged groups, is still needed.

Secondly, empirical data indicate that the differences in well-being associated with the first-level digital divide are still pronounced. A recent study using the European Social Survey data for Luxembourg [33] has found that, controlling for demographics, differences in life satisfaction between Internet users and non-users were stronger than those between light and heavy Internet users. They also found that Internet use was positively associated with life satisfaction more strongly than with happiness and that the benefits of Internet use were higher for the younger generations and for those not satisfied with their income.

The present study attempted to examine the differences in well-being associated with the first-level digital divide (operationalized as having Internet access at home) in a probability sample of community dwellers in one of the poorest areas of London. The household survey included questions on Internet access alongside several measures of well-being, including the Trait Hope Scale (THS), General Health Questionnaire (GHQ-12) and a one-item subjective happiness measure. In this paper we report the associations between Internet access and levels of well-being, while taking into account other lifestyle factors and demographic characteristics.

The study was largely based on the theoretical model proposed by DiMaggio et al. [31], which postulates that demographic and situational factors affect the quality of equipment, as well as Internet use skills, autonomy, and social support. These three factors influence the efficacy, intensity, and purposes of Internet use which leads to increases in human capital and social capital (including educational attainment, increased earnings, political agency, social participation). In line with this model, we hypothesized that the 
Internet would offer individuals information about educational, career, and community participation opportunities, as well as serve as means for maintaining social connections, contributing to the resources for coping with life challenges. We looked for evidence of the contribution of Internet access to psychological well-being (happiness, hope, and subjective health), controlling for demographic variables.

The objectives of the study were mainly exploratory, but our analysis was focused on two main research questions: 1) Does Internet access predict unique variance in subjective well-being when demographic factors (such as gender, age, education, level of income, and country of origin) are controlled? 2) Is the contribution of Internet access to well-being mediated by social ties, social support, and community participation?

\section{MATERIALS AND METHODOLOGY}

\subsection{Context}

A cross-sectional household survey among adults (16 years or over) was conducted at randomly selected addresses in six deprived areas in the London Borough of Redbridge. These areas included Clementswood, Loxford, Valentines, Hainault and the Orchard and Tiptree neighbourhoods. The survey was administered using structured face-to-face interviews and examined health and wellbeing in these deprived communities with the focus on diet, physical activity, use of healthcare services, mental health and well-being. The survey was commissioned by the local Primary Care Trust (health authority) as part of a health needs assessment among its most deprived communities [34]. An earlier publication used the same dataset to investigate a different set of research questions concerning the associations between physical activity and the extent of social environment [35].

\subsection{Sample}

Addresses in each target area were selected from the Post Office Address File using simple probability sampling. The total population of the six selected areas was 47,198 people. All eligible adults residing at the selected addresses were invited to take part in the survey. The response rate at the household level was 53\% over all neighbourhoods, with a maximum of $68 \%$ in Loxford and a minimum of $43 \%$ in Valentines. These rates compare extremely well with the rates achieved for recent postal surveys in Redbridge of around $28 \%$, particularly given these are the poorest and most diverse areas in Redbridge. At the individual level the adjusted response rate was $45 \%$ overall, ranging from $28 \%$ in Valentines to $65 \%$ in Clementswood. The 800 participant sample included 350 males $(43.8 \%)$ and 447 females $(55.9 \%)$, three respondents failing to report their gender. The median age was 36 years (quartile range 22 years). The majority of the respondents $(91 \%)$ had secondary or a higher level of education.

The study was approved by the Research Ethics Committee of the University of East London. The purpose, the aims of the study, and the way the data collected would be used were explained to all participants, both verbally and in writing. Informed written consent was obtained in all cases, and the participants were informed of their right to withdraw their consent at any time without explanation and at no consequence.

\subsection{Data Management}

Completed questionnaires and associated consent forms were returned in batches by interviewers and checked for completeness and plausibility by staff on receipt. A subset of respondents was telephoned by the survey team to confirm that they had, indeed, given the interview. Anonymised questionnaires were entered into an electronic database. Each record was back verified against the written questionnaire. One in 10 questionnaires was back checked a second time by different team member. The data set was transferred to SPSS for data management, cleaning and analysis. No extreme or implausible data were identified and all cases were included in subsequent analysis.

The number of missing data points did not exceed $10 \%$ for any variable, except for the reported individual and household income (37.6\% and $40.8 \%$, respectively). Because we could not assume these income values to be missing-atrandom, they were not used in the structural equation modeling. In the other analyses missing data were pairwise deleted.

\subsection{Measures}

\subsubsection{Well-being Measures}

Happiness. A one-item overall subjective happiness measure: "Taking all things together, would you say you are..." with four response options ranging from "very happy" to "not at all happy".

Trait Hope Scale (THS) [36] is an 8-item instrument based on Snyder's cognitive model of hope which defines it as a positive state derived from our perception of different possible pathways to a desired outcome and agency, or motivation to use these pathways. The scale contains two fouritem subscales, agency and pathways (reliability coefficients for these and all other composite scales are presented in Table 2 below). Responses are given on a 6-point scale.

General Health Questionnaire (GHQ) [37] is a 12-item instrument that measures positive and negative aspects of perceived mental health, expressed as positive mental health and symptoms of mental disorder, respectively. Four-point scoring was used. Existing studies indicate that these two dimensions, although weakly correlated, can be viewed as independent and that positive scale can be used as a measure of positive mental health or well-being [38].

\subsubsection{Internet Access and other Lifestyle Measures}

Education was measured on a 5-point nominal scale: "primary", "secondary (GCSE or equivalent)", "A-level or equivalent", "university degree", "other" (the latter was treated as missing data).

The survey included a number of items assessing different lifestyle variables, including an item "Do you have Internet access at home" with three answer options: "yes, broadband", "yes, dial-up", "no".

The household and individual respondent incomes were measured on an 8-band ordinal scale. One additional item assessed subjective difficulty in managing on family income (5-point scale, ranging from "very easy" to "very difficult"). 
Self-reported disability was measured using 3 items assessing mobility problems, self-care problems, and problems performing everyday activities (3-point response scale).

Social involvement was measured by 7 items, including: "How often do you personally..." ("meet up with relatives", "speak to relatives on the phone", "write to relatives", "meet up with friends", "speak to friends on the phone", "write to friends", "speak to neighbours"). A 5-point scale was used for the answers, ranging from "most days", "once a week or more", "once or twice a month", "less often than once a month" to "never".

Three items assessed social support, including: "How many people..." (would help you with shopping, would lend you money, would advise/support you in crisis). Four answer options were provided: "none", "one or two", "more than two", "would not ask" (during the analysis, "none" and "would not ask" answer options were grouped).

Physical activity was measured using a short form of the International Physical Activity Questionnaire (IPAQ: [39]). The questionnaire includes 7 items, asking the respondent to indicate the number of days they engaged in vigorous physical activity, moderate physical activity, and walking in the last 7 days. For each of these types of activity and for sitting, the respondents are asked to indicate the number of hours and minutes spent.

Creative activities involvement was assessed using by an item "In the last 12 months have you done any of these activities?", with 11 answer options provided: "dance", "sang to an audience", "rehearsed or performed a play", etc.

Cultural event attendance was assessed by an item "In the last 12 months have you been to any of these events", with 9 answer options being "film at a cinema", "exhibition or collection of art", "event connected with books or writing", etc.

\section{RESULTS}

\subsection{Internet Access and Lifestyle}

Because the number of dial-up users was extremely small $(\mathrm{N}=12)$, they were grouped together with broadband users to form the Internet access group $(\mathrm{N}=602 ; 75.3 \%$ of the sample), which was compared to the no-access group $(\mathrm{N}=181$; $22.6 \%$ of the sample). Seventeen respondents who gave no answer to the internet access question were excluded from the analysis. The demographic composition and comparison between the two groups are presented in Table 1. Chi-square test was used to compare the two groups on nominal variables, Mann-Whitney test was used for ordinal variables, and Student's t test was used for interval variables.

The groups did not differ significantly in gender distributions. The respondents having Internet access (Internet connection owners) were younger $(\mathrm{M}=37.1, \mathrm{SD}=14.7)$ than those in the no-access group $(\mathrm{M}=47.3, \mathrm{SD}=18.9)$ and had higher education levels. They were more likely to be employed or engaged in full-time studies, whereas those with no Internet access were more likely to be unemployed, disabled, or retired. Respondents with Internet access had higher average household income, as well as individual income, and admitted that it was easier for them to manage on their household income, compared to respondents having no
Internet access at home. However, respondents in the Internet access group had larger average household size compared to the no-access group.

The association between lifestyle variables and Internet access was also explored. The Internet access group members were more likely to write to relatives $(Z=4.96 ; p<.001)$, meet with friends $(Z=2.03 ; p<.05)$, speak to friends $(Z=2.68$; $p<.01)$, and write to friends $(Z=5.75 ; p<.001)$, yet less likely to speak to neighbours $(Z=3.49 ; p<.001)$, compared to those in the no-access group. They also reported higher social support, indicating a larger number of people who would lend them money $(Z=2.78 ; \mathrm{p}<.01)$ or support them in crisis $(Z=2.17 ; p<.05)$. The results indicated that respondents with Internet access engaged in a wider repertoire of creative activities and visited more diverse cultural events. However, respondents having Internet access at home reported spending more hours sitting on a week day, compared to those in the no-access group; this remained significant $(\mathrm{p}<.01)$ after age was controlled. All the other differences in physical activities in the two groups were explained by age.

Because $55.0 \%$ of the surveyed community dwellers were not born in the UK, we also explored the differences between the groups in the country of origin and the number of years lived in the UK. We found that the proportion of migrants in the no-access group was smaller and that migrants with Internet access at home had, on average, lived fewer years in the UK, compared to those with no Internet access. The highest percentage of Internet access was found among respondents born in India or Sri Lanka (93.06\%), Pakistan or Bangladesh (86.24\%), followed by those born in Africa $(77.61 \%)$, other countries $(72.90 \%)$ and, finally, the UK $(68.70 \%)$. When only respondents under 35 were compared, the observed pattern remained the same, and the differences between the Internet access and no-access group were still significant $(\mathrm{p}<.001)$ : India or Sri Lanka $(\mathrm{N}=64$, 96.88\%), Pakistan or Bangladesh $(\mathrm{N}=43,97.67 \%)$, Africa $(\mathrm{N}=22,90.91 \%)$, other countries $(\mathrm{N}=48,77.08 \%)$, and the UK $(\mathrm{N}=150,74.67 \%)$.

\subsection{Internet Access and Well-being}

The matrix of associations between the study variables are presented in Table 2 .

The questionnaire scores for the two groups were compared using Student's t-test. A number of significant differences were revealed (Table 3 ). Internet connection owners reported fewer negative symptoms on the GHQ, which resulted in a lower GHQ overall score. In addition, Internet connection owners scored higher on Agency subscale of the THS. A more detailed analysis indicated that differences on all four items belonging to the Agency subscale were significant between the two samples, as opposed to all the Pathways subscale items. Internet connection owners also reported higher overall happiness.

The following analyses were performed in two stages. At the first stage, we aimed to find out whether the associations between Internet connection ownership and well-being could be explained by basic demographic variables (sex, age, education, income, and place of birth). At the second stage, we tried to find out whether the associations between Internet access and well-being would be mediated by lifestyle variables. 
Table 1. Composition of the internet access and no-access group.

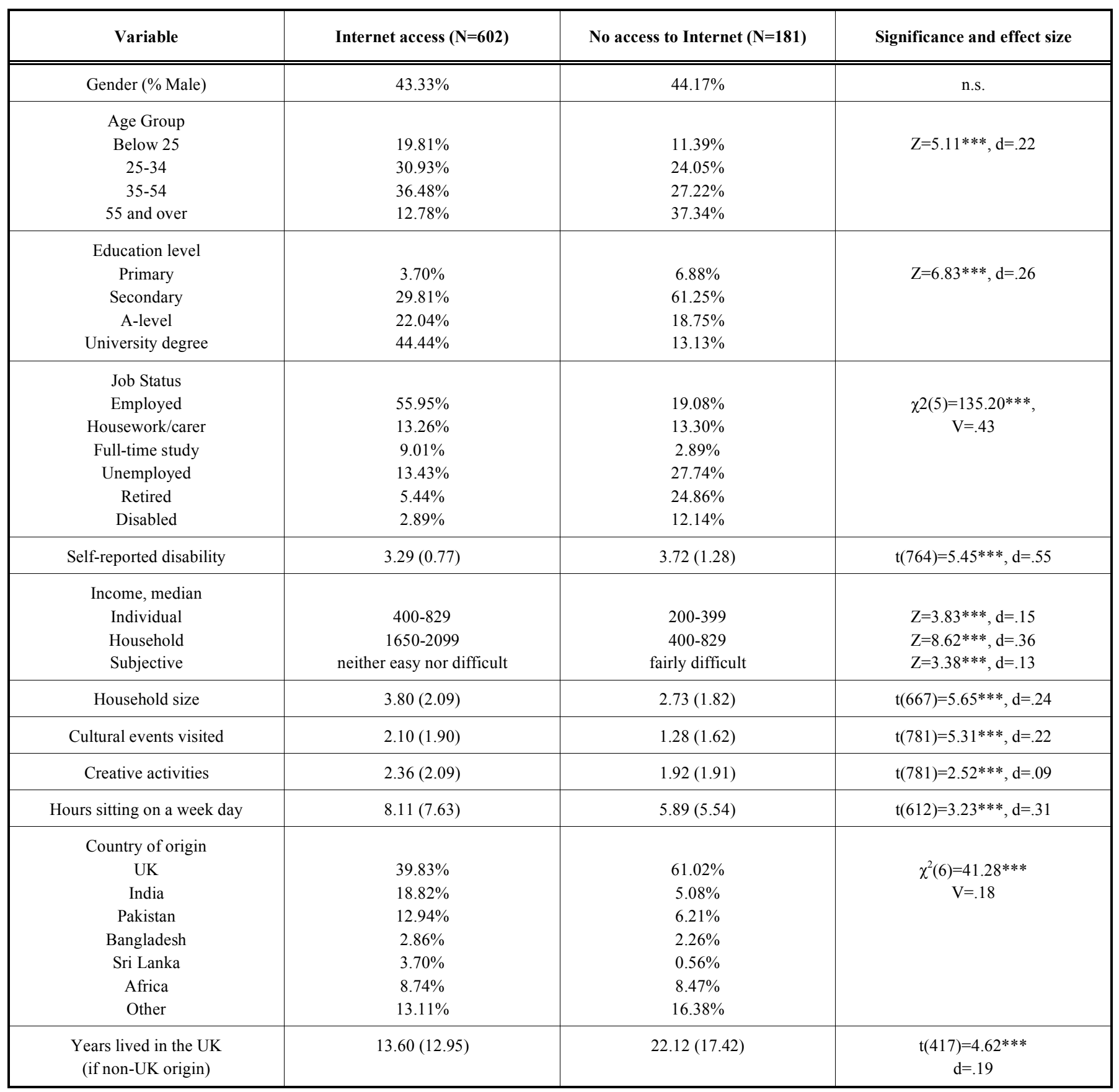

Note: $* * * \mathrm{p}<.001$, means with standard deviations are given for interval scales and composites.

Because several study variables were measured by multiple indicators, structural equation modeling was used. First, a measurement model for each scale (THS, GHQ, social support, social involvement, cultural event participation, creative activity engagement) was tested in Mplus 7.11 using MLR estimator, which is robust with respect to non-normal distributions and implements the full-information maximum likelihood approach for handling missing data. WLSMV estimator was used to evaluate scales with less than 4 response categories per variable [40]. Fit indices were examined to ensure acceptable fit $(\mathrm{CFI}>0.9$, RMSEA $<0.08)$. These criteria were met for all scales with the exception of social ties $(\mathrm{CFI}=.975, \mathrm{RMSEA}=.10$ after two items with low factor loadings were excluded).

After this, path models and latent variable models were constructed, with one set of dependent variables (two GHQ subscales, two THS subscales, and overall happiness item) in turn. There were five observed control variables: gender, age, education level, country of birth (UK / non-UK), and subjective income. The control variables were entered as predictors of dependent variables and of Internet access, which, in turn, predicted the dependent variables. All 3 models fit the data well. The models for overall happiness and hope are presented on Figs. (1 and 2), respectively. 
Table 2. Reliabilities and pairwise Spearman correlations between the study variables.

\begin{tabular}{|c|c|c|c|c|c|c|c|c|c|c|c|c|c|c|c|c|c|c|}
\hline & Alpha & 1 & 2 & 3 & 4 & 5 & 6 & 7 & 8 & 9 & 10 & 11 & 12 & 13 & 14 & 15 & 16 & 17 \\
\hline $\begin{array}{c}\text { 1. Sex } \\
(1=\text { Male, } \\
2=\text { Female })\end{array}$ & $\mathrm{n} / \mathrm{a}$ & & -.00 & -.02 & $-.09 *$ & -.01 & $-.10 * *$ & .00 & .04 & -.00 & $-.13 * * *$ & .04 & -.01 & -.04 & $.15 * * *$ & -.03 & $-.08 *$ & .03 \\
\hline 2. Age & $\mathrm{n} / \mathrm{a}$ & 708 & & $-.28 * * *$ & -.06 & .02 & $-.11 * *$ & $.35 * * *$ & -.07 & $.41 * * *$ & $.31 * * *$ & $-.26 * * *$ & $-.22 * * *$ & -.06 & .01 & .01 & -.01 & -.03 \\
\hline 3. Education & $\mathrm{n} / \mathrm{a}$ & 712 & 635 & & $.14 * * *$ & $.26 * * *$ & -.03 & $-.10 * *$ & .04 & $-.26 * * *$ & -.05 & $.20 * * *$ & $.26^{* * *}$ & .05 & -.07 & .02 & .00 & -.07 \\
\hline $\begin{array}{c}\text { 4. Subjective } \\
\text { Income }\end{array}$ & .74 & 727 & 649 & 654 & & -.02 & .12 & $-.13 * * *$ & .02 & $-.15 * * *$ & $.07 *$ & $.12 * *$ & $.13 * * *$ & -.05 & $-.19 * * *$ & $.10 * *$ & .00 & $.18 * * *$ \\
\hline $\begin{array}{c}\text { 5. Place of } \\
\text { birth }(1=\mathrm{UK}, \\
2=\text { non-UK) }\end{array}$ & $\mathrm{n} / \mathrm{a}$ & 786 & 703 & 708 & 721 & & $-.48 * * *$ & -.05 & -.04 & .00 & $.10^{* *}$ & .00 & $.18 * * *$ & .01 & .07 & .02 & -.00 & -.01 \\
\hline $\begin{array}{l}\text { 6. English } \\
\text { level }\end{array}$ & $\mathrm{n} / \mathrm{a}$ & 791 & 706 & 712 & 725 & 784 & & $.10 * *$ & .03 & $-.18 * * *$ & $-.21 * * *$ & $.11 * *$ & .02 & .06 & $-.12 * * *$ & $.17 * * *$ & $.18 * * *$ & $.10 * *$ \\
\hline $\begin{array}{l}\text { 7. Self- } \\
\text { reported } \\
\text { Disability }\end{array}$ & .79 & 776 & 695 & 698 & 715 & 769 & 773 & & $-.08 *$ & $.26 * * *$ & $-.14 * * *$ & $-.20 * * *$ & $-.20 * * *$ & $-.11 * *$ & $.26 * * *$ & $-.22 * * *$ & $-.26 * * *$ & $-.22 * * *$ \\
\hline $\begin{array}{l}\text { 8. Social } \\
\text { Support }\end{array}$ & .83 & 727 & 647 & 656 & 673 & 723 & 725 & 717 & & $-.14 * * *$ & $-.17 * * *$ & $.14 * * *$ & .07 & .05 & $-.10 * *$ & $.14 * * *$ & $.15 * * *$ & $.15 * * *$ \\
\hline 9. Social Ties & .72 & 729 & 653 & 656 & 675 & 724 & 727 & 719 & 684 & & $.35^{* * *}$ & $.39 * * *$ & $.21 * * *$ & .06 & $-.17 * * *$ & $.25 * * *$ & $.18 * * *$ & $.14 * * *$ \\
\hline $\begin{array}{c}\text { 10. Creative } \\
\text { Activities }\end{array}$ & .69 & 797 & 711 & 715 & 730 & 789 & 794 & 779 & 730 & 732 & & $.54 * * *$ & $.09 *$ & $-.10 * *$ & .00 & $.16^{* * * *}$ & $.18 * * *$ & .07 \\
\hline $\begin{array}{c}\text { 11. Cultural } \\
\text { Events }\end{array}$ & .70 & 797 & 711 & 715 & 730 & 789 & 794 & 779 & 730 & 732 & 800 & & $.22 * * *$ & $-.08 *$ & -.02 & $.18 * * *$ & $.18 * * *$ & $.07 *$ \\
\hline $\begin{array}{c}\text { 12. Internet } \\
\text { access } \\
(0=\text { none } \\
1=\text { yes })\end{array}$ & $\mathrm{n} / \mathrm{a}$ & 780 & 698 & 700 & 719 & 772 & 777 & 766 & 719 & 722 & 783 & 783 & & .00 & $-.09 *$ & $.10 * *$ & .04 & $.11 * *$ \\
\hline $\begin{array}{l}\text { 13. GHQ } \\
\text { Positive }\end{array}$ & .84 & 758 & 679 & 679 & 699 & 754 & 756 & 749 & 700 & 701 & 761 & 761 & 747 & & $-.13 * * *$ & $.12 * * *$ & $.12 * *$ & $.17 * * *$ \\
\hline $\begin{array}{l}\text { 14. GHQ } \\
\text { Negative }\end{array}$ & .83 & 765 & 684 & 685 & 707 & 760 & 763 & 755 & 708 & 710 & 768 & 768 & 755 & 745 & & $-.39 * * *$ & $-.35 * * *$ & $-.43 * * *$ \\
\hline $\begin{array}{l}\text { 15. Hope } \\
\text { Agency }\end{array}$ & .81 & 752 & 677 & 679 & 696 & 747 & 749 & 741 & 697 & 703 & 755 & 755 & 741 & 727 & 735 & & $.72 * * *$ & $.43 * * *$ \\
\hline $\begin{array}{l}\text { 16. Hope } \\
\text { Pathways }\end{array}$ & .81 & 739 & 668 & 668 & 684 & 736 & 737 & 731 & 686 & 690 & 742 & 742 & 730 & 715 & 724 & 723 & & $.35 * * *$ \\
\hline $\begin{array}{l}\text { 17. Happi- } \\
\text { ness }\end{array}$ & $\mathrm{n} / \mathrm{a}$ & 760 & 681 & 679 & 702 & 754 & 758 & 747 & 702 & 706 & 763 & 763 & 749 & 738 & 744 & 732 & 718 & \\
\hline
\end{tabular}

Note: ${ }^{* * *} \mathrm{p}<.001,{ }^{* *} \mathrm{p}<.01,{ }^{*} \mathrm{p}<.05$; sample sizes for each correlation coefficient are given in the lower triangular matrix; values for composite scales were calculated as sum scores

After the demographic variables were controlled, Internet access remained a weak, yet significant $(\mathrm{p}<.01)$ predictor of overall happiness. Age, education level, subjective income, and country of origin were significant unique predictors of Internet access, suggesting that the Internet access would more likely be present in the homes of younger people with higher levels of education and income, who are more likely to be migrants. Predictably, subjective income was associated with happiness. The inverse association of education with happiness may reflect the demographic composition of the area. When self-reported disability (modelled as a latent factor) was included in the model as a control variable, the regression coefficient for happiness dropped to .09 , but remained significant $(\mathrm{p}<.05)$.

The results for trait hope were similar. Internet access was the only significant predictor of the agency aspect of hope, although it was not significantly related to pathways. The only significant link between demographic variables and 
Table 3. Well-being scores in the Internet access $(\mathrm{N}=525)$ and no-access $(\mathrm{N}=145)$ groups.

\begin{tabular}{|c|c|c|c|c|c|c|}
\hline Scale & \multicolumn{2}{|c|}{ Mean } & \multicolumn{2}{|c|}{ Standard deviation } & $\begin{array}{c}\text { t value } \\
(\mathrm{df}=668)\end{array}$ & Cohen's d \\
\hline GHQ Negative & 9.75 & 10.97 & 3.50 & 4.60 & $-3.43 * * *$ & .32 \\
\hline GHQ Total & 25.96 & 27.52 & 5.13 & 5.51 & $-3.19 * *$ & .30 \\
\hline Hope Pathways & 19.14 & 18.92 & 3.34 & 3.19 & 0.71 & .07 \\
\hline Hope Sum & 37.97 & 36.66 & 6.36 & 6.87 & $2.15^{*}$ & .20 \\
\hline Happiness & 3.24 & 3.04 & 0.66 & 0.79 & $3.12 * *$ & .29 \\
\hline
\end{tabular}

Note: ${ }^{* * *} \mathrm{p}<.001,{ }^{* *} \mathrm{p}<.01,{ }^{*} \mathrm{p}<.05$

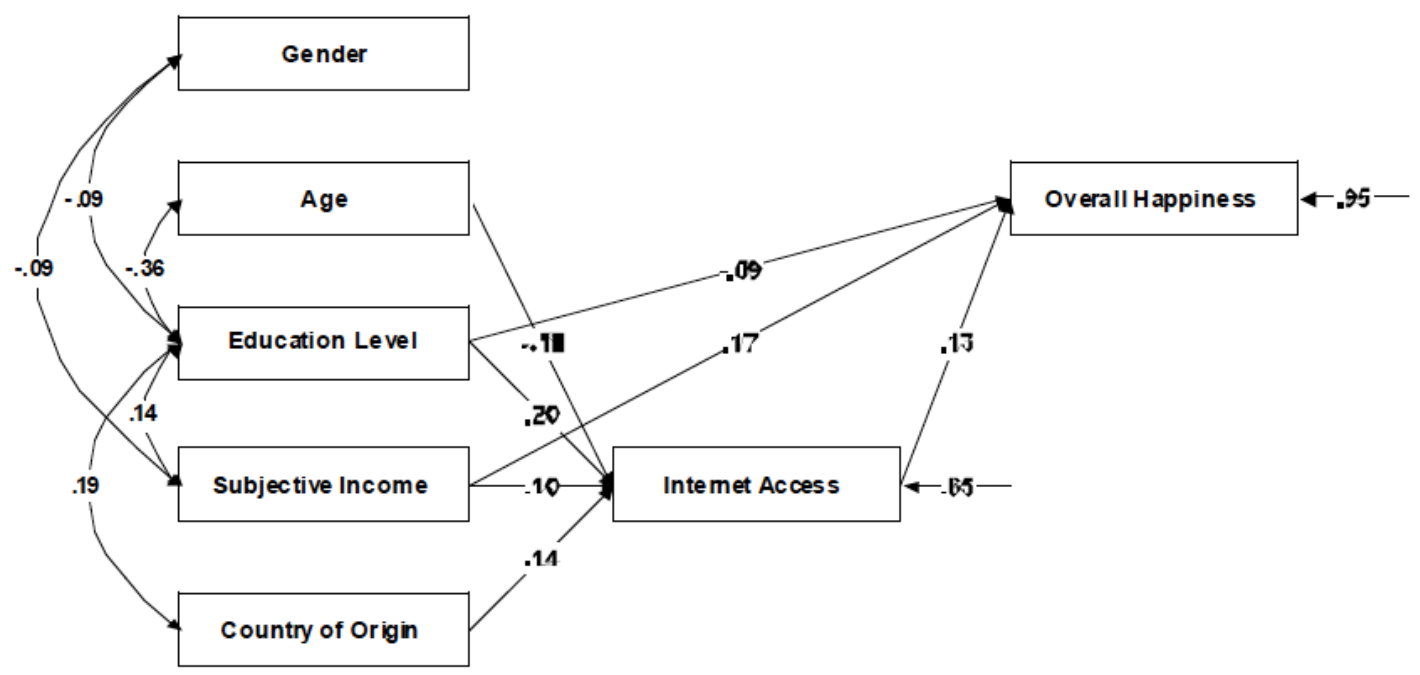

Fig. (1). Path diagram of associations between demographic predictors, Internet access, and overall happiness (N=800). Note: MLR estimator, $\chi^{2}(4)=2.29, \mathrm{p}=.68, \mathrm{CFI}>.999, \mathrm{RMSEA}<.001$; standardized coefficients are presented; all parameters significant at $\mathrm{p}<.05$.

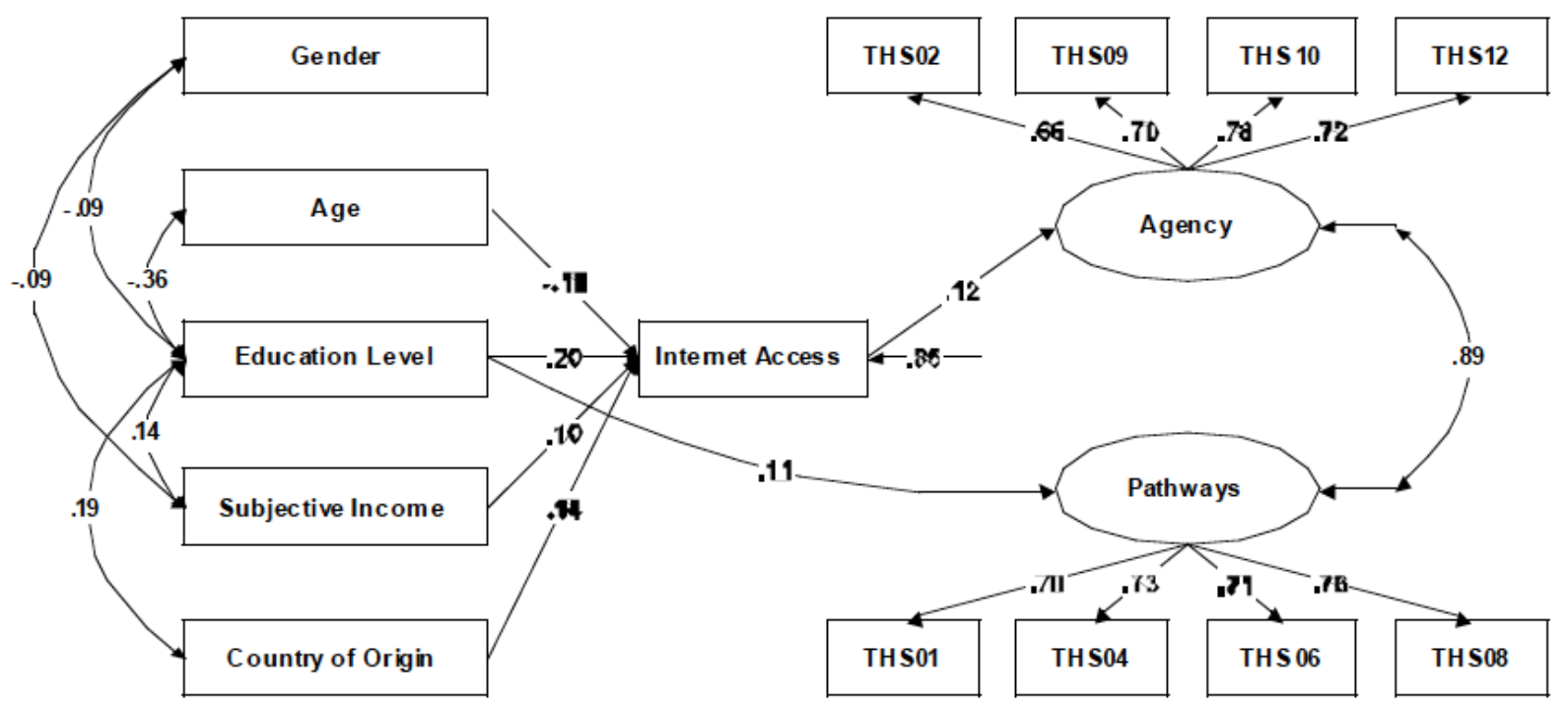

Fig. (2). Structural model of the associations between demographic predictors, Internet access, overall happiness, and THS subscales $(\mathrm{N}=800)$. Note: MLR estimator, $\chi^{2}(55)=165.66, \mathrm{p}<.001, \mathrm{CFI}=.945$, RMSEA=.050; standardized coefficients are presented; all parameters significant at $\mathrm{p}<.05$. 


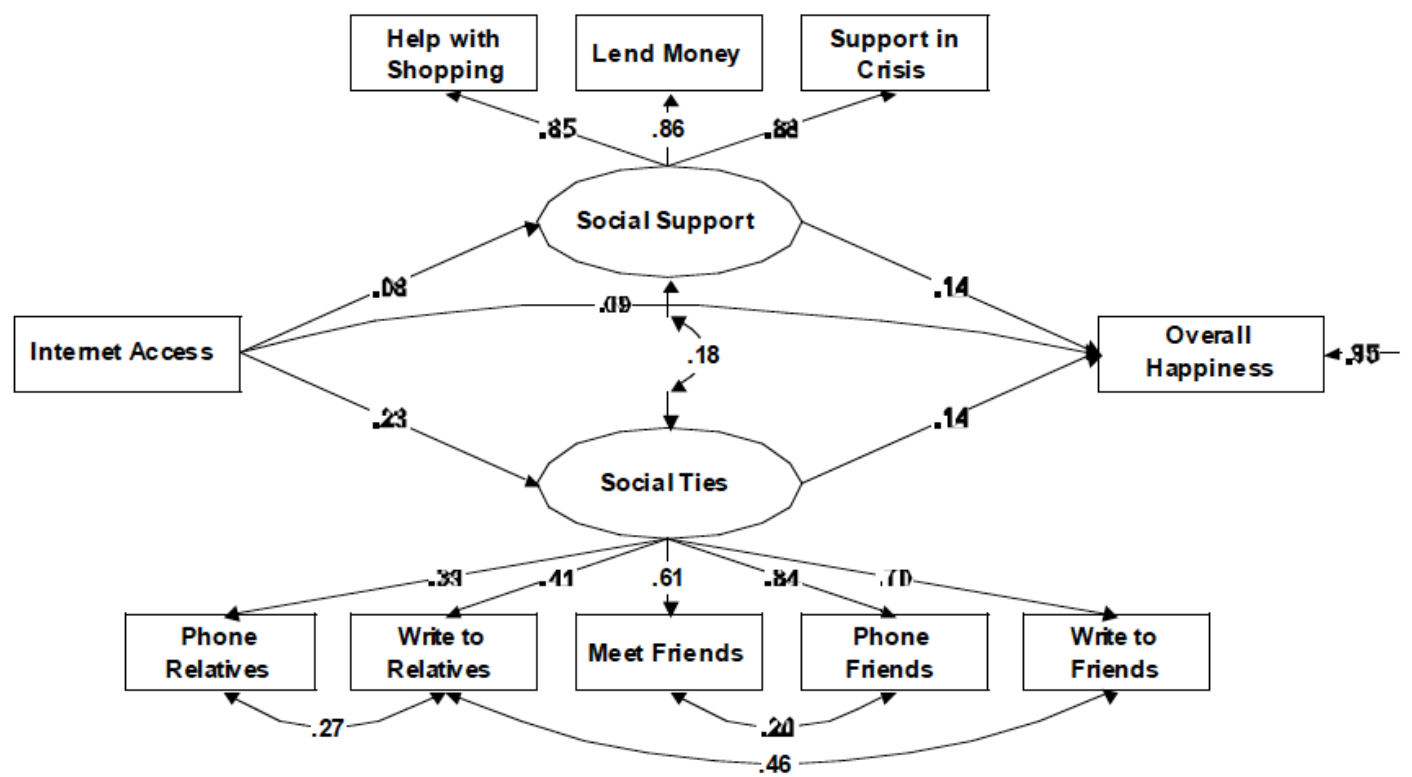

Fig. (3). Structural model of mediated effect of Internet access on overall happiness $(\mathrm{N}=782)$. Note: WLSMV estimator, $\chi^{2}(28)=124.98$, $\mathrm{p}<.001, \mathrm{CFI}=.980, \mathrm{RMSEA}=.067$; standardized coefficients are presented; all parameters significant at $\mathrm{p}<.05$.

subscales of the THS was the association of pathways with education level, suggesting that educated people are more confident in their ability of finding ways to solve difficult life situations. The results were similar for the negative subscale of the GHQ $\left(\chi^{2}(111)=260.65, p<.001\right.$, CFI $=.943$, RMSEA=.041; figure not presented for brevity), which was inversely predicted by subjective income $(\mathrm{r}=-.21, \mathrm{p}<.001)$ Internet access $(\mathrm{r}=-.12, \mathrm{p}<.01)$, and associated with gender $(\mathrm{r}=.12, \mathrm{p}<.01)$. The positive subscale of the GHQ was not significantly associated with any of the predictors included in the model.

In order to find out the variables that mediate the association between Internet access and happiness, structural equation modeling was used. We hypothesized that Internet access provides means for people to be more socially integrated by staying in touch with friends and relatives, obtaining social support, finding out information about cultural events, participating in community creative activities. However, participation in cultural events and community creative activities were not related to the overall happiness and their associations with Internet access were explained by education and income; as a result, we decided to exclude these two variables from the final model (Fig. 3).

The model demonstrated acceptable fit to the data. The coefficient of association between Internet access and the overall happiness item remained significant, suggesting that the joint variance of these variables could only be partially explained by social connections. The indirect effect of Internet access on overall happiness mediated by social ties was significant $(\mathrm{r}=.077, \mathrm{SE}=.032, \mathrm{p}=.015)$, providing support for partial mediation. The indirect effect mediated by social support was not significant $(\mathrm{r}=.027, \mathrm{SE}=.016, \mathrm{p}=.097)$. The total standardized indirect effect of Internet access on happiness was small $(r=.043, p=.004)$ in comparison to the total effect $(r=.134, p=.001)$, suggesting other potential links between these variables. We did not include control variables in the model, because it is currently not possible to use the
MLR estimator for this model type and the WLSMV estimator is less robust against missing data [41]. However, when the subsample of employed respondents $(\mathrm{N}=361)$ was analyzed separately, the indirect effect of Internet access on overall happiness remained significant $(\mathrm{r}=.051, \mathrm{SE}=.022$, $\mathrm{p}=.021)$.

Finally, in order to explore the variables moderating the links between Internet access and well-being, we applied hierarchical multiple regression using centered (age, education, household size, subjective income, subjective health) or dummy coded (gender, Internet access, job status, place of birth) variables. Because of the large number of variables and the presence of missing data, we entered demographic predictors with one at a time with Internet access at first step of the regression, followed by an interaction term at the second step. We examined the cases where both the increase in the variance explained by the interaction term and its respective regression coefficient were significant at least at $\mathrm{p}<.05$. For overall happiness, we found weak interaction effects for gender $\left(\Delta R^{2}=.006, p=.027\right)$, education $\left(\Delta R^{2}=.006, p=.045\right)$, subjective income $\left(\Delta \mathrm{R}^{2}=.014, \mathrm{p}=.001\right)$, country of origin $\left(\Delta \mathrm{R}^{2}=.007, \mathrm{p}=.023\right)$. For hope, the only interaction effect was found for subjective income $\left(\Delta \mathrm{R}^{2}=.006, \mathrm{p}=.046\right)$. For the GHQ, the only weak interaction effect was found for gender $\left(\Delta \mathrm{R}^{2}=.006, \mathrm{p}=.026\right)$. These findings indicate that the links between Internet access and well-being are marginally stronger for males, immigrants, and individuals with lower levels of education and income.

\section{DISCUSSION}

The Internet transforms lives by enabling people to solve their everyday problems in more time-efficient ways and by providing information about new opportunities. Data from the deprived areas of East London provide a new snapshot of the digital divide. Although it can be argued that access to the Internet has become nearly universal and that it is more relevant now to conceptualize digital divide as individual 
differences in the ability (rather than opportunity) of using the new technological tools [31], still, a large proportion of household residents in a major European city have not progressed beyond the first level of the digital divide. The demographic differences between those who do and do not have Internet access at home are in line with existing findings that lack of Internet access is mostly peculiar to socially disadvantaged groups. The penetration of the Internet in the UK has increased since the data were collected, but the proportion of those who have never used the Internet is still over $10 \%[32]$.

Individuals having Internet access at home are more likely to be younger, engaged in work or study, and recent immigrants. Despite having more people in their place of habitat, Internet connection owners also have higher household and individual income and find it easier to manage on the money at their disposal. They report engaging in more creative activities and visiting more cultural events, and are also more likely to write and speak to their relatives and friends, compared to individuals with no Internet access. Despite having fewer health issues, Internet connection owners report spending more hours sitting down on week days. In contrast, individuals with no Internet connection at home present a picture of social disengagement.

The differences in psychological well-being between respondents who do and do not have Internet access at home are substantial. Controlling for demographic variables, Internet connection owners report higher well-being, in terms of feeling more hopeful, exhibiting less negative mental disorder symptoms, and feeling happier. The absence of significant effects for the positive subscale of the GHQ is consistent with its weak $(\mathrm{r}<.2)$ correlations with the other 4 wellbeing indicators that were moderately $(r>3)$ interrelated. This may be explained by the fact that the positive GHQ items are phrased in a way that reflects absence of ill-being ("able to concentrate", "capable of making decisions"), rather than presence of well-being.

Several of the above findings are consistent with previous research outcomes. Thus, for example, our data on higher cultural activities participation confirms and extends the existing results [21-23] on the off-line community participation of Internet users. In a similar vein, consistent with findings on the benefits of the Internet on the social support and relationship development [13, 17], our results suggest increased interactions with relatives and friends through written and face-to-face communication. Overall, the results of this study add to the body of knowledge, unravelling the complex relationships between the multidimensional constructs of Internet use and well-being.

Though gender, age, education, and origin do not explain the link between Internet access and well-being, the role of income in determining this relationship does not seem to be definite. In our data, individual income did not explain this association, but household income did, to some extent, although the validity of this self-reported indicator was questionable, because of missing data. It should be noted that the effect sizes for the association between Internet access and well-being variables are modest (Cohen's $d<.30$, partial $\eta^{2}$ in the .01-.05 range). This is reasonable, given the number of different factors that contribute to well-being, and corresponds well to similar data from other countries [33].
We explored the possible variables mediating these associations and found evidence in favour of the hypothesis that the Internet is associated with higher well-being by means of providing opportunities for maintaining social ties and for obtaining social support. This result is in line with existing findings, suggesting the positive effects of online social interaction $[8,9]$. Absence of statistically significant effects of creative activities and community participation as mediating variables suggests that the effects of these variables might be weaker or contingent on other factors, such as education or individual goals of Internet use. The moderation effects we found indicate that Internet access is associated with psychological well-being more strongly in more socially disadvantaged groups (individuals with lower income and education, immigrants). However, the small size of these effects calls for replication in larger and more socially diverse samples, using more reliable happiness measures, before conclusions can be drawn.

The non-experimental nature of the study forbids making any inferences about the direction of causality [42, 43]. Theoretically, the causal links between Internet access and psychological well-being in residents of deprived neighbourhoods may go in both directions: on the one hand, information technologies provide people with means to improve their lives, leading to higher well-being; on the other hand, higher levels of well-being (hope, optimism, self-efficacy) may serve as psychological resources that motivate active improvement of one's life situation, which involves the adoption of new technologies. However, because the most likely alternative explanations (such as income, age, and education) have been controlled and because the former direction of causality seems to be more plausible, given existing research $[2,44]$, we believe that our findings contribute to the body of data suggesting a positive effect of the Internet on the well-being of socially disadvantaged populations. Future studies using experimental, longitudinal, and qualitative approaches may help clarify the psychological mechanisms behind this effect, as well as the specific reasons why members of socially disadvantaged groups refrain from taking advantage of contemporary information technology.

\section{CONCLUSION}

Clearly, despite early speculations, the Internet is not emerging as the new social evil, but can rather be conceptualised as an indicator of enhanced psychological functioning, subject to its balanced and responsible use. The mechanisms by which the Internet usage has an impact on health and well-being are still largely unclear and for the most part would depend upon what people do on-line. However, it is evident that even the mere fact of Internet access is a potential enabler for many population sub-groups living in deprived circumstances. Further research is, as always, needed to continue unravelling the complexities of our psychological relationship with one of the greatest discoveries of the $20^{\text {th }}$ century.

\section{CONFLICT OF INTEREST}

The authors confirm that this article content has no conflict of interest. 


\section{ACKNOWLEDGEMENTS}

The data were collected as part of Healthy Redbridge household survey commissioned by NHS Redbridge. Support from the Basic Research Program of the National Research University Higher School of Economics is gratefully acknowledged.

\section{REFERENCES}

[1] Kraut RE, Patterson M, Lundmark V, Mukhopadhyay T, Scherlis W. Internet paradox: a social technology that reduces social involvement and psychological well-being? Am Psychol 1998; 53: 1017-32.

[2] Kraut R, Kiesler S, Boneva B, Cummings JN, Helgeson V, Crawford AM. Internet paradox revisited. J Soc Issues 2002; 58: 49-74.

[3] Valkenburg PM, Peter J. Internet communication and its relationship to well-being: Identifying some underlying mechanisms. Media Psychol 2007; 9: 43-58.

[4] Huang $\mathrm{C}$ Internet use and psychological well-being: A metaanalysis. Cyberpsychol Behav Soc 2010; 13: 241-9.

[5] Sum S, Mathews RM, Hughes I, Campbell A. Internet use and loneliness in older adults. Cyberpsychol Behav 2008; 11: 208-11.

[6] Weiser EB. The functions of Internet use and their social and psychological consequences. Cyberpsychol Behav 2001; 4: 723-43.

[7] Jackson LA, Fitzgerald HE, Zhao Y, Kolenic A, von Eye A, Harold R. Information Technology (IT) use and children's psychological well-being. Cyberpsychol Behav 2008; 11: 755-7.

[8] Valenzuela S, Park N, Lee KF. Is there social capital in a social network site?: facebook use and college students' life satisfaction, trust, and participation. J Comput-Mediat Comm 2009; 14: 875901 .

[9] Oh JH, Ozkaya E, LaRose R. How does online social networking enhance life satisfaction? The relationships among online supportive interaction, affect, perceived social support, sense of community, and life satisfaction. Comput Hum Behav 2013; 30: 69-78.

[10] Griffiths M. Internet addiction: fact of fiction? Psychologist 1998; 12: 24650 .

[11] Putnam RD. The strange disappearance of civic America. Am Prospect 1996; 24: 34-46.

[12] Nie NH, Hillygus DS. Where does Internet time come from? A reconnaissance. IT Society 2002; 1: 1-20.

[13] Bargh JA, McKenna KYA. The Internet and social life. Ann Rev Psychol 2004; 55: 573-90.

[14] Freese J, Rivas S, Hargittai E. Cognitive ability and Internet use among older adults. Poetics 2006; 34: 236-49.

[15] Liu X, LaRose R. The effects of the Internet on college students' school life satisfaction. Cyberpsychol Behav 2008; 11: 310-20.

[16] Leung L. Impact on net-generation attitudes, seductive properties of the Internet, and gratifications obtained on Internet use. Telematics Informatics 2003; 20: 107-29.

[17] McKenna KY, Bargh JA. Plan 9 from cyberspace: the implications of the Internet for personality and social psychology. Pers Soc Psychol Rev 2000; 4: 57-75.

[18] Drentea P, Goldner M, Cotten S, et al. The association among gender, computer use and online health searching, and mental health. Info Comm S 2008; 11: 505-25.

[19] LaRose R, Mastro DA, Eastin MS. Understanding Internet usage: A social cognitive approach to uses and gratifications. Soc Sci Comp Rev 2001; 19: 395-413.

[20] Chen H, Wigand RT, Nilan M. Exploring Web users' optimal flow experiences. Info Technol Internet 2000; 13: 263-78.

[21] Katz JE, Rice RE, Aspden P. The Internet, 1995-2000. Am Behav Scientist 2001; 45: 405-19.
Gross EF, Juvonen J, Gable SL. Internet use and well-being in adolescence. J Soc Issues 2002; 58: 75-90.

Wellman B, Haase AQ, Witte J, Hampton K. Does the Internet increase, decrease, or supplement social capital? social networks, participation, and community commitment. Am Behav Scientist 2001; 45: 437-56.

[24] Subrahmanyam K, Lin G. Adolescents on the new: Internet use and well-being. Adolescence 2007; 42: 659-77.

[25] Cotten SR. Students' Technology Usage and the Impacts on WellBeing. New Direct Student Serv 2008; 124: 55-70.

[26] Valkenburg PM, Peter J. Adolescents and the Internet: A decade of research. Curr Issues Psychol Sci 2009; 18: 1-5.

[27] Sum S, Mathews M, Pourghasem M, Hughes I. Internet technology and social capital: How the Internet affects seniors' social capital and wellbeing. J Comput Mediat 2008; 14: 202-20.

[28] Sum S, Mathews M, Hughes I, Campbell A. Internet use as a predictor of sense of community and wellbeing in older people. $\mathrm{Cy}$ berpsychol Behav 2009; 12: 235-39.

[29] Chen Y, Persson A. Internet use among young and older adults: relation to psychological well-being. Educ Gerontol 2002; 28: 731 44.

[30] Hargittai E, Hsieh YP. Digital inequality. In: Dutton WH, ed. oxford handbook of internet studies. Oxford: Oxford University Press 2013; pp. 129-50.

[31] DiMaggio P, Hargittai E, Celeste C, Shafer S. Digital inequality: From unequal access to differentiated use. In Neckerman KM, Ed. Social Inequality, N.Y.: Russell Sage Foundation 2004; pp. 355 400.

[32] Office for National Statistics, Internet Access Quarterly Update. Office for National Statistics 2014. URL: http://www.ons.gov.uk ons/dcp171778_362910.pdf

[33] Pénard T, Poussing N, Suire R. Does the Internet make people happier? J Soc Econ 2013; 46: 105-16.

[34] Institute for Health and Human Development. Healthy Redbridge: Executive Summary. 2009. URL: http://www.uel.ac.uk/ wwwme$\mathrm{dia} /$ microsites/ihhd/Exec-Summ-WC-Master-230309.pdf

[35] Yu G, Renton A, Wall M, Estacio E, Cawley J, Datta P. Prevalence of low physical activity and its relation to social environment in deprived areas in the London borough of Redrbidge. Soc Indic Res 2011; 104: 311-22.

[36] Snyder CR, Harris C, Anderson JR, Holleran SA, Irving LM, Sigmon ST. The will and the ways: Development and validation of an individual-differences measure of hope. J Pers Soc Psychol 1991; 60: $570-85$.

[37] Goldberg D, Williams P. A user's guide to the General Health Questionnaire, Windsor. UK: NFER-Nelson 1988.

[38] Hu Y, Stewart-Brown S, Twigg L, Weich S. Can the 12-item General Health Questionnaire be used to measure positive mental health? Psychol Med 2007; 37: 1005-13.

[39] Craig CL, Marshall AL, Sjöström M, et al. International physical activity questionnaire: 12-country reliability and validity. Med Sci Sports Exerc 2003; 35: 1381-95.

[40] Byrne BM. Structural equation modeling with mplus: basic concepts, applications, and programming. N.Y.: Routledge 2013

[41] Muthén LK, Muthén BO. Mplus user's guide, Seventh Ed. Los Angeles, CA: Muthén \& Muthén 2012.

[42] Wegener DT, Fabrigar LR. Analysis and design for nonexperimental data: Addressing causal and noncausal hypotheses. In Reis HT, Judd CM, Eds. Handbook of Research Methods in Social and Personality Psychology, Cambridge, UK: Cambridge University Press 2000; pp. 412-450.

[43] Mulaik SA. Linear causal modeling with structural equations. Boca Raton, FL: CRC Press 2009.

[44] Goldfarb A, Prince J. Internet adoption and usage patterns are different: Implications for the digital divide. Inf Econ Policy 2008; 20: $2-15$.

(C) Boniwell et al.; Licensee Bentham Open.

This is an open access article licensed under the terms of the Creative Commons Attribution Non-Commercial License (http://creativecommons.org/licenses/by-nc/3.0/) which permits unrestricted, non-commercial use, distribution and reproduction in any medium, provided the work is properly cited. 